\title{
THE RATIONALE TO SWITCH FROM POSTOPERATIVE HYPERFRACTIONATED ACCELERATED RADIOTHERAPY TO PREOPERATIVE HYPERFRACTIONATED ACCELERATED RADIOTHERAPY IN RECTAL CANCER
}

\author{
Philippe A. Coucke, ${ }^{* \dagger}$ Britta Sartorelli, ${ }^{*}$ Jean-François Cuttat, ${ }^{\ddagger}$ Wendy Jeanneret, ${ }^{*}$ \\ Michel GILlet ${ }^{\ddagger}$ AND RenÉ-Olivier MirimanofF* ${ }^{\dagger}$
}

\author{
*Department of Radiation-Oncology, ${ }^{\dagger}$ Laboratory of Radiobiology and Flow Cytometry, ${ }^{\ddagger}$ Department of Surgery, \\ Centre Hospitalier Universitaire Vaudois, CHUV, Lausanne, Switzerland
}

\begin{abstract}
Purpose: To demonstrate the feasibility of preoperative Hyperfractionated Accelerated RadioTherapy (preop-HART) in rectal cancer and to explain the rationales to switch from postoperative HART to preoperative HART.

Methods and Materials: Fifty-two consecutive patients were introduced in successive Phase I trials since 1989. In trial 89-01, postoperative HART ( $48 \mathrm{~Gy}$ in 3 weeks) was applied in 20 patients. In nine patients with locally advanced rectal cancer, considered unresectable by the surgeon, $32 \mathrm{~Gy}$ in 2 weeks was applied prior to surgery (trial 89-02). Since 1991, $41.6 \mathrm{~Gy}$ in 2.5 weeks has been applied preoperatively to 23 patients with T3-T4 any N rectal cancer immediately followed by surgery (trial 91-01). All patients were irradiated at the department of radiation-oncology with a four-field box technique (1.6 Gy twice a day and with at least a 6-h interval between fractions). The minimal accelerating potential was $6 \mathrm{MV}$. Acute toxicity was scored according to the World Health Organization (WHO for skin and small bowel) and the Radiation Therapy Oncology Group criteria (RTOG for bladder). This was done weekly during treatment and every 3 months thereafter. Small bowel volume was estimated by a modified "Gallagher's" method.

Results: Acute toxicity was acceptable both in postoperative and preoperative setup. The mean acute toxicity was significantly lower in trial 91-01 compared to 89-01. This difference was due to the smaller amount of small bowel in irradiation field and lower total dose in trial 91-01. Moreover, there was a significantly reduced delay between surgery and radiotherapy favoring trial 91-01 (median delay 4 days compared to 46 days in trial 89-01). Nearly all patients in trial 89-02 and 91-01 underwent surgery (31 out of 32; 97\%). Resection margins were negative in 29 out of 32. Hospitalization duration in trial 91-01 was not significantly different from trial 89-01 (19 vs. 21 days, respectively).

Conclusions: Hyperfractionated accelerated radiotherapy immediately followed by surgery is feasible as far as acute toxicity is concerned. Preoperative HART is favored by a significantly lower acute toxicity related, in part, to a smaller amount of irradiated small bowel, and a shorter duration of the delay between radiotherapy and surgery. Moreover, the hospital stay after preoperative HART is not significantly increased.
\end{abstract}

Hyperfractionation, Acceleration, Preoperative radiotherapy, Rectal cancer.

\section{INTRODUCTION}

The mainstay of treatment in rectal cancer is surgery $(16$, 33,38 ). The actuarial risk of local recurrence rate after surgery alone is high especially for infiltrative rectal cancer (UICC T3-T4) and positive lymph node involvement $(29,38,43)$. Radiation therapy has been proposed as an adjuvant treatment modality both in pre- or postoperative setup $(11,44,45)$. In 1989 , we ran a Phase I trial aimed at introducing a hyperfractionated accelerated schedule in a postoperative setup (trial 89-01) (8). The rationale to accelerate was based on the rapid occurrence of local recurrence after surgery. Moreover, as stated by Cox et $a l$, there is a continuous need to study "fractionation in
Presented at the Fifth EORTC Symposium on Research, Diagnosis and Treatment of Gastrointestinal Cancer, Porto, Portugal, April, 1993; International Congress of Radiation Oncology (ICRO), Kyoto, Japan, June, 1993; CERRO-9, Clinical and Experimental Research in Radiation Oncology, Les Menuires, France, January, 1994.
Reprint requests to: Dr. Philippe A. Coucke, Department of Radiation-Oncology, CHUV, Bugnon, 1011 Lausanne, Switzerland.

Accepted for publication 13 October 1994. 
radiotherapy as an important modality to be pursued in clinical studies." Those fractionation studies serve as "the background for the investigation of adjuncts such as chemical modifiers, hyperthermia, as well as integrated treatment with cytotoxic chemotherapy and/or surgical resection" (9). The hypothesis of rapid proliferation of rectal cancer cells at the origin of recurrence has been confirmed recently by in vivo assessment of potential doubling time $\left(\mathrm{T}_{\mathrm{pot}}\right)(3,36,48,54)$. Radiobiological models predict a better outcome for a shorter duration of overall treatment time, especially for rapidly cycling tumor cells, i.e., having a small $\mathrm{T}_{\text {pot }}(8,12,13,55,56)$. The feasibility of postoperative hyperfractionated accelerated radiotherapy (postop-HART; 48 Gy in 3 weeks) has recently been published (8). However, the median delay between surgery and initiation of adjuvant postop-HART was considered to be long, especially if fast-cycling cells were left after surgery.

In head and neck cancer and breast cancer, it has been shown that delaying the onset of adjuvant radiation might have a deleterious effect on local control and, hence, survival $(6,52)$. This is thought to be due to induction of proliferative activity of residual clonogenic cells after resection of the tumor bulk (52). This induction of proliferation of residual tumor cells might be linked to the appearance of growth factors, which is known to occur as a basic physiological mechanism in the wound-healing process.

The long delay between the two treatment modalities in trial 89-01 and the feasability of preoperative lowdose HART (trial 89-02; 32 Gy in 2 weeks for patients considered unresectable at presentation) formed the basis for the initiation of trial 91-01. In this latter Phase I trial, the preoperative dose was increased to $41.6 \mathrm{~Gy}$ in 2.5 weeks followed immediately by surgery. Patients with T3-T4 any $\mathrm{N}$ rectal cancer were eligible for this Phase I trial. We report the feasability of trial 91-01 and explain the different reasons favoring preoperative HART as compared to postoperative HART in T3-T4 any $\mathrm{N}$ rectal cancer.

\section{METHODS AND MATERIALS}

In trial 89-01, a total dose of 48 Gy was applied postoperatively in 3 weeks. Patients not eligible for 89-01, because they were deemed unresectable at presentation, were included in 89-02 (32 Gy in 2 weeks followed rapidly by surgery). Since 1991, patients with Stage cT3T4 (c = clinically staged as opposed to pathologic staging) any $\mathrm{N}$ rectal cancer were systematically introduced in trial 91-01 (41.6 Gy in 2.5 weeks followed by surgery within 6 days).

Prior to the initiation of the treatment, all patients underwent a complete clinical examination, blood count, assessment of renal and hepatic function, and CEA dosage. Distant metastatic disease was excluded by chest $\mathrm{X}$ ray and abdominal ultrasound or computed tomography
(CT scan). For patients enrolled in the preoperative HART trials, the assessment of the local extent of the tumor was done by digital examination, completed by rectal ultrasound and/or CT scan.

All patients were irradiated at the department of Radiation Oncology at CHUV with a lincar accelerator with a minimal accelerating potential of $6 \mathrm{MV}$ (clinac 2100 or linac 75-5). The dose per fraction was $1.6 \mathrm{~Gy}$, and the interfraction interval was at least $6 \mathrm{~h}$. The dose prescription was at the intersection of the fields (box technique). The homogeneity was within $5 \%$ of the dose prescribed at the isocenter.

The field margins were defined according to a "standard field," as described by Gunderson (18). The upper limit was located at the L5-S1 interspace. The lower limit was decided in function of the localization of the primary tumor. For low-located tumors, i.e., within a range of $5 \mathrm{~cm}$ from the anal margin, this latter was included in the treatment volume. For lesions located higher than $5 \mathrm{~cm}$, the exclusion of the anal margin was checked by in vivo dosimetry using TLDs. Corrections of the lower limit were done if required.

Acute toxicity was assessed at least once a week during treatment and coded according to the WHO scale for skin and bowel and according to the RTOG scale for bladder. The treatment was never interrupted for acute toxicity. We focused our attention on small bowcl toxicity because this was the dose-limiting toxicity in postop-HART. The small bowel toxicity was calculated as a mean value over the whole treatment period. For preoperative and postoperative HART, a correction of this mean toxicity score was done if patient initially presented with transit symptoms, i.e., diarrhea. The mean increase rather than the absolute values were compared between both trials. Corrections were required for three patients in trial 89-01 and seven patients in trial 91-01.

The amount of small bowel was estimated prior to the initiation of radiation treatment at the simulation. On those simulation films, the total surface of small bowel, both in anterioposterior and lateral fields, was calculated by superimposing a $1 \mathrm{~cm}$ spread grid (taking into account the magnification factor) (14). Surfaces of small bowel were expressed as a percent of total surface of the field after a correction has been made for individually shaped small bowel blocks.

Quantitative data such as small bowel surface, duration of treatment delay, and mean toxicity scores were compared with a two-sided $t$-test. Differences were considered significant if a $0.05 p$-value was reached.

\section{RESULTS}

The feasibility of postoperative HART (trial 89-01) has been recently published (8). The dose-limiting factor in this Phase I trial was small bowel toxicity.

Trial 89-02 was characterized by a "negative" selec- 
Table 1. Overview of tumor characteristics

Tumor characteristics $(89-01,89-02,91-01)$

\begin{tabular}{lcccccccrr}
\hline $48 \mathrm{~Gy}$ & $\mathrm{pT}$ & $\mathrm{pN}+$ & $\mathrm{Rec}$. & $32 \mathrm{~Gy}$ & $\mathrm{cT}$ & $\mathrm{cN}+$ & $41.6 \mathrm{~Gy}$ & $\mathrm{c}$ 1 & $\mathrm{cN}+$ \\
\hline pT2 & 1 & 0 & & $\mathrm{cT2}$ & & & $\mathrm{cT} 2$ & & \\
pT3 & 14 & 7 & & cT3 & 2 & $1^{*}$ & cT3 & 9 & $5^{*}$ \\
pT4 & 3 & 1 & & cT4 & 7 & $5^{*}$ & cT4 & 14 & $8^{*}$ \\
Total & 18 & 8 & 2 & Total & 9 & $6^{*}$ & Total & 23 & $13^{*}$ \\
\hline
\end{tabular}

* Positive or unknown. pT and pN: pathological staging in contrast to clinical staging (cT and $\mathrm{cN}$ ).

tion of patients. Those patients were not considered eligible for immediate surgery because the local extent of the tumor (Table 1). All received 32 Gy in 2 weeks followed by surgery. Acute toxicity was minor and there were no treatment interruptions. Five patients underwent abdominoperineal resection and four, a low anterior resection (Table 2). All patients underwent a complete resection except one. The feasibility of preoperative low-dose HART in locally advanced rectal cancer and the high resectability ratio has served as the basis for conducting trial 91-01. In this latter trial, the preoperative dose has been raised to $41.6 \mathrm{~Gy}$, and surgeons were asked to keep the interval between preoperative HART and surgery as short as possible, preferentially within 6 days.

The patient characteristics of trial 89-01 and 91-01 are summarized in Table 3 . The age distribution was comparable. However, the tumor was more often located close to the anal margin in the preoperative trial (median distance $3 \mathrm{~cm}$ as compared to $6 \mathrm{~cm}$ ). Nevertheless, the acute toxicity in trial 91-01 was acceptable. There was no report of acute small bowel toxicity exceeding Grade 2 WHO. There were no treatment interruptions. The mean corrected small bowel toxicity in trial 91-01 was significantly lower compared to trial 89-01 $(p=0.02)$ (Table 4). This reduction of acute small bowel toxicity can be explained both by the lower total dose in trial 91-01 and by the significantly smaller amount of small bowel within the irradiation fields. The respective median values of small bowel, expressed in percent of the surface of the irradiation field, were $26 \%$ (range $0-46 \%$ ) for lateral fields and $10 \%$ (range $0-21 \%$ ) for anterior fields in trial 89-01, compared to, respectively, $0 \%$ (range $0-12 \%$ ) and $6 \%$

Table 2. Type of surgery and resectability in preoperative HART

\begin{tabular}{lcccc}
\hline \multicolumn{4}{c}{ Resectability ratio in preoperative HART } \\
\hline & Number & APR & LAR & Resectability* \\
\hline 41.6 Gy & 23 & 16 & 6 & 21 \\
32 Gy & 9 & 5 & 4 & 8 \\
Total & 32 & $21+10=31(97 \%)$ & $29 / 32=91 \%$ \\
\hline
\end{tabular}

* Defined as complete resection with distal, proximal, and radial margin negative at pathological examination. (range 0-29\%) in trial 91-01. Those differences are statistically significant $(p<0.001)$.

The timing between both treatment modalities was also significantly different (Table 5). The median delay between surgery and postoperative HART in 89-01 is 46 days (mean value 55 ), whereas in 91-01, this delay was 4 days (mean value 6 days) $(p<0.001$ ). The duration of hospitalization after surgery has been compared. The preoperative approach could be at the origin of an increased perioperative morbidity. If this would be the case, we should expect an increased hospital stay for postoperative complications directly related to the preoperative treatment. Although there was a trend towards a prolonged hospital stay in trial 91-01 (29 vs. 26 days; $p=$ 0.1 ), the median value of hospitalization duration in 9101 was shorter than in trial 89-01 (respective median values: 19 vs. 21 days). The postoperative morbidity in 91-01 was characterized by wound-healing delay in three patients with abdominoperineal resection and one abscess formation after a low anterior resection. Although most of the patients presented with T4 rectal cancer in the 8902 and 91-01 trial, all except one single patient were submitted to surgical resection of the tumor. This single patient presented initially with a very advanced rectal cancer infiltrating the sacral bone, the gluteal mass with fistulization at the skin. This patient was submitted to preoperative HART (41.6 Gy) and readressed to the surgeon, who decided that this tumor was definitely unresectable. Radiation therapy was immediately continued (twice-a-day $1.6 \mathrm{~Gy}$ with a field-size reduction) until the cumulative dose of $64 \mathrm{~Gy}$ was reached. This patient tolerated this high dose accelerated local treatment well and remains alive in partial remission, more than 1 year after treatment. The remaining 31 patients (trials 89-01 and 91-01) were submitted to a surgical procedure (21 abdominoperineal and 10 low anterior resections). Twenty-nine out of 31 patients underwent a curative resection (Table 2 ). This latter was defined as surgery resulting in a negative proximal, distal, and radial margin.

Until now there is only one report of long-term toxicity, i.e., occurring at more than 6 months after completion of radiotherapeutic treatment, in patients treated in trial 8901 . This single patient had a bladder necrosis likely to be due in part to the aggressiveness of the initial surgical 
Table 3. Overview of patient characteristics trial 91-01 and 89-01

\begin{tabular}{llll}
\hline Minimum & Maximum & Mean & Median \\
\hline
\end{tabular}

Patient characteristics (41.6 Gy): Trial 91-01

$\begin{array}{lrrrr}\text { Age } & 27 & 85 & 61 & 62 \\ \text { Distance to } & & & & \\ \quad \text { A.M. (cm) } & 0 & 12 & 3.9 & 3 \\ \text { Delay RT-S } & 1 & 17 & 6 & 4 \\ \text { FU-months } & 3 & 30 & 8 & 7 \\ \text { Hosp (days) } & 11 & 106 & 29 & 19\end{array}$

Patient characteristics (48 Gy): Trial 89-01

\begin{tabular}{lrrcc} 
Age & 42 & 76 & 64 & 66 \\
Distance to & & & & \\
$\quad$ A.M. & 2 & 20 & 7.1 & 6 \\
Delay RT-S & 31 & 141 & 55 & 46 \\
FU-months & 5 & 40 & 23 & 25 \\
Hosp (days) & 12 & 57 & 26 & 20.5 \\
\hline
\end{tabular}

(A.M. = anal margin; FU = follow-up; Hosp $=$ hospitalization; $\mathrm{RT}=$ radiotherapy).

procedure with nearly complete devascularization of this organ for oncological reasons. In trial 89-01, the median follow-up reaches 34 months. Thirteen out of 20 patients are alive with no evidence of disease. Three patients died of local progression and five of distant metastases (one patient with local progression had simultaneously distant metastases). However, in two out of these three, local recurrences were found in patients treated by postoperative HART after salvage surgery for a recurrence. The median follow-up in trial 91-01 reaches 19 months. There was only one report of a late complication in this Phase I trial (grade 3 small bowel toxicity).

The pathologic staging (pT) has been compared with the clinical staging (cT) in trial 91-01 (Fig. 1). The clinical staging, i.e., digital examination completed by rectal ultrasound or CT-scan, seems to be suboptimal. There is a frequent mismatch betwecn preoperative assessment of T-stage and pathologic assessment of infiltration (Fig. 1). It cannot be excluded, however, that there is a downstaging on the tumor even after a short delay between preoperative irradiation and surgery. For $\mathrm{N}$-staging, both rectal ultrasound and CT-scan seem to be unreliable for assessment of nodal involvement prior to the treatment.

In summary, the results for both modalities (postoperative HART 48 Gy vs. preoperative HART $41.6 \mathrm{~Gy}$ ) are illustrated in Table 6 and Table 7.

\section{DISCUSSION}

Both local recurrence and distant metastases after surgery remain a major problem in the curative approach of rectal cancer. Adjuvant radiation therapy can reduce the incidence of local recurrence and, therefore, this treatment modality is currently considered as a part of the standard treatment (33). This adjuvant radiation treatment can be given pre-, post-, or intraoperatively $(17,34,39,46,47)$. Both for postoperative and preoperative trials, published data are available about the potential impact of adjuvant radiation therapy on local control in rectal cancer $(2,10$, $15,20,21,24,32,34,35,37,40,42,49,51)$.

In a postoperative adjuvant setup there is a trend to combine both radiation therapy and chemotherapy to obtain an increase in local effect and a spatial cooperation $(10,24,41,49)$. The association, compared to single modality treatment, results in a better local effect and an increased survival $(10,24,49)$. The question of the local effect of adjuvant postoperative radiation therapy alone remains unsolved, as illustrated by the results of the Dutch Multicenter Trial $(7,51)$. Optimization of the postoperative schedules is still possible (1). However, our hypothesis is that the delay between both treatment modalities could be too long. The importance of the delay in the occurrence of local recurrence has not yet been proven, especially in rectal cancer, although it has shown its potential importance for other localizations $(6,52)$. Theoretically, the appearance of growth factors related to scar formation may be at the origin of stimulation of growth of residual clonogens in the surgical bed. The addition of chemotherapy to postoperative radiotherapy has been done in different trials. Chemotherapy is needed in conjunction with irradiation to accomplish a systemic as well as a local effect (41). Our alternative approach for postoperative treatment, initiated in 1989 , was to increase the effect of the radiation by accelerating the treatment (8).

Table 4. Overview of technical details of treatment fields in trial 91-01 and 89-01

\begin{tabular}{rrrr} 
Minimum & Maximum Mean \\
\hline
\end{tabular}

Treatment characteristics (41.6 Gy): Trial 91-01

$\begin{array}{lrrrr}\text { Lat. }\left(\mathrm{cm}^{2}\right) & 223 & 481 & 333 & 323 \\ \text { AP }\left(\mathrm{cm}^{2}\right) & 247 & 480 & 350 & 333 \\ \text { Lat-c }\left(\mathrm{cm}^{2}\right) & 199 & 457 & 299 & 295 \\ \text { AP-c }\left(\mathrm{cm}^{2}\right) & 208 & 393 & 297 & 291 \\ \text { Lat-SB }\left(\mathrm{cm}^{2}\right) & 0 & 37 & 6 & 0 \\ \text { Ap-SB }\left(\mathrm{cm}^{2}\right) & 0 & 101 & 31 & 21 \\ \text { \%SB-Lat-c } & 0 & 12 & 2 & 0 \\ \text { \%SB-AP-c } & 0 & 29 & 10 & 6\end{array}$

Treatment characteristics (48 Gy): Trial 89-01

\begin{tabular}{lrrrr} 
Lat. $\left(\mathrm{cm}^{2}\right)$ & 239 & 442 & 322.5 & 319 \\
AP $\left(\mathrm{cm}^{2}\right)$ & 264 & 510 & 354 & 352 \\
Lat-c $\left(\mathrm{cm}^{2}\right)$ & 201 & 405 & 287 & 292 \\
AP-c $\left(\mathrm{cm}^{2}\right)$ & 210 & 404 & 294 & 282 \\
Lat/SB & 0 & 49 & 24 & 26 \\
AP-SB & 0 & 112 & 74 & 76 \\
\%SB-Lat-c & 0 & 21 & 9 & 10 \\
\%SB-AP-c & 0 & 46 & 27 & 26 \\
\hline
\end{tabular}

(AP = anteroposterior field; Lat $=$ lateral field; $\mathrm{SB}=$ small bowel surface in $\mathrm{cm}^{2} ; \mathrm{c}=$ corrected, i.e., taking into account the individually shaped small bowel blocks). 
Table 5. Comparison between the "time-factors" in trial $91-01$ and $89-01$

\begin{tabular}{lcccc}
\hline & \multicolumn{4}{c}{ Time factor } \\
\cline { 2 - 5 } & \multicolumn{2}{c}{$\begin{array}{c}\text { Preoperative } \\
\text { HART }^{(41.6)}\end{array}$} & \multicolumn{2}{c}{$\begin{array}{c}\text { Postoperative } \\
\text { HART }^{(48)}\end{array}$} \\
\hline Delay RT/S & 6 & 4 & 55 & 46 \\
Hosp & 29 & 19 & 26 & 21 \\
Dur. RT & 25 & 23 & 21 & 21 \\
& Mean & Median & Mean & Median \\
\hline
\end{tabular}

(Dur. RT = duration of radiation treatment, Hosp = hospitalization stay after surgery and delay between radiotherapy and surgery - delay RT/S - are expressed in days).

Although the treatment was feasible as far as acute toxicity was concerned, the rather long delay between surgery and the inititiation of the adjuvant accelerated hyperfractionated radiotherapy was a matter of concern, especially since rectal cancer is characterized by fast cellular kinetics $(36,48)$. Recently published values for potential doubling time $\left(\mathrm{T}_{\mathrm{pot}}\right)$, assessed by Iodo-deoxy-uridine (Iudr) injection and flow cytometric measurement of labeling index and $\mathrm{Ts}$, seem to confirm our concern $(3,36,48,54)$. The published $T_{\text {por }}$ values in rectal cancer are even shorter than those measured in head and neck cancer (54). Finally, the dose-limiting small bowel toxicity observed in trial 89 01 (postoperative $48 \mathrm{~Gy}$ in 3 weeks), prohibits any further increase in the intensity of the treatment by, for example, combination with chemotherapy (8).

The feasibility of "low-dose" ( 32 Gy in 2 weeks) hyperfractionated accelerated radiotherapy in "unresectable" rectal cancer (trial 89-02), and the high resectability ratio obtained in this small series, served as the basis for initiation of a "moderate dose" preoperative Phase I trial. The dose increment between trial 89-02 and trial 91-91 was in accordance to the dose response data obtained by an extensive review of the literature $(15,20,21,32,35$, $37,40,42$ ). Low-dose radiotherapy has no significant

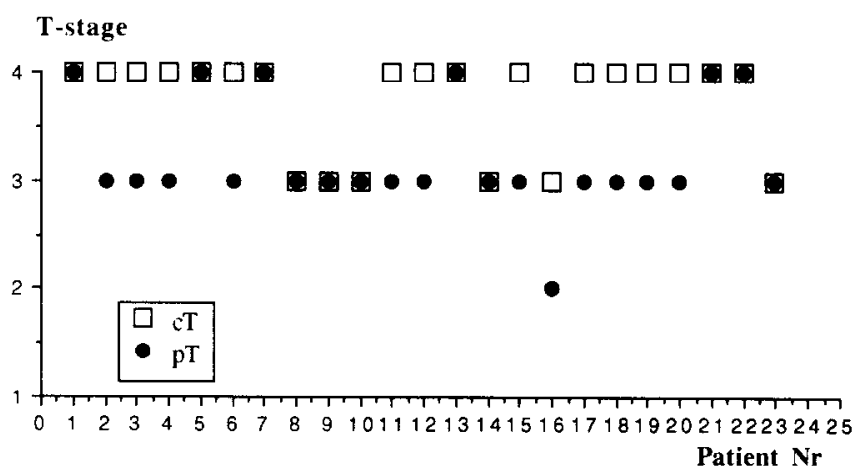

Fig. 1. Clinical $\mathrm{T}$-stage (cT $=$ open squares) compared with patholigical T-stage ( $\mathrm{pT}=$ closed circles). The observed mismatch could eventually be explained by downstaging or inaccuracy of the methods (digital examination and rectal ultrasound and/or computed tomography) to assess local extent of the tumor prior to preoperative radiation therapy. effect on local control $(20,32,37,40)$, whereas doses higher than $20 \mathrm{~Gy}$ seem to significantly affect local recurrence rate $(15,42)$. It is interesting to note that both in the Stockholm Trial and in the EORTC 40761 trial there is a positive impact of radiation on pelvic control. These latter trial are characterized by a "short" delay $(<2$ weeks) between both treatment modalities $(15,42)$. Therefore, we assume that in other trials, especially the VASAG II and the EORTC 40741 trials, the prolongation of the interval might have cancelled the effect of the preoperative treatment at a dose level where one should await an impact on local control $(4,21)$.

Attempts to modify the intensity and, hence, the efficacy of preoperative radiotherapy are currently under investigation $(5,11,19,25-28,30,31,47,50,53)$. The enhancement of the therapeutic effect might be obtained by accelerating the treatment or adding chemotherapy. Again, the overall treament time might be important in this particular choice. To keep the total treatment duration of the local combined approach (i.e., radiotherapy and surgery) as short as possible, we decided to accelerate the treatment preoperatively and reduce the interval between both modalities. The median interval in the present series is only 4 days. Some authors involved in the search of optimized preoperative radiation treatment argue that the delay between radiotherapy and surgery is beneficial especially for tumor shrinkage and reduction of local inflammatory postradiation reaction. This tumor shrinkage is illustrated by reports of high resectability ratio $(5,19$, $22,23,25-28,30,31,50$ ). However, comparison of resectability ratios is hampered by variations in preoperative staging and definition of locally advanced or marginally resectable rectal cancer. Most of our patients presented initially with T3-T4 in any $\mathbf{N}$ rectal cancer and a large proportion of those patients (29 out of 32) underwent a "curative resection" (= negative margin inclusive radial margins), although the median interval between both treatment modalities was only 4 days.

Any increase of the radiation-related surgical morbidity would preclude further exploitation of the potential benefit of the reduction of the overall treatment time. In our hands, the hospitalization duration after surgery was not increased as compared to our initial postoperative series. The feasibility of this new approach by other centers has

Table 6. Comparison of small bowel toxicity trial 91-01 and 89-01

\begin{tabular}{lccc}
\hline & \multicolumn{3}{c}{ Toxicity scores (WHO) } \\
\cline { 2 - 4 } df* & Mean X-Y & Paired $t$-value & Prob. two-tailed \\
\hline 2 & 0.317 & 7.181 & 0.018 \\
\hline
\end{tabular}

Mean toxicity scored according to WHO criteria on day 0 , $7,14,21$. Corrections made in the preoperative and postoperative group if patient presented initially with diarrhea. $n=20$ in both groups. $\mathrm{df}=$ degrees of freedom. 
Table 7. Summary of the differences between trial 91-01 and 89-01

Comparison preoperative HART vs. postoperative HART

\begin{tabular}{lccc}
\hline $\begin{array}{c}\text { Median values } \\
\text { Mean values }\end{array}$ & $\begin{array}{c}\text { Preoperative } \\
41.6 \mathrm{~Gy}\end{array}$ & $\begin{array}{c}\text { Postoperative } \\
48 \mathrm{~Gy}\end{array}$ & $p$-Value \\
\hline Hospitalization & 19 & 21 & \\
& 29 & 26 & 0.1 \\
Interval RT/S (days) & 4 & 46 & \\
& 6 & 55 & $<0.001$ \\
Toxicity-WHO* & 0.3 & 0.6 & 0.018 \\
\%SB-AP(c) & 6 & 26.3 & \\
& 10.4 & 26.5 & $<0.001$ \\
\%SB-Lat(c) & 0 & 9.7 & \\
& 2.2 & 9.1 & $<0.001$ \\
\hline
\end{tabular}

Interval RT/S = delay between RT (radiotherapy) and surgery (S), expressed in days; \%SB = small bowel surface in percent of field surface corrected (c) for individual blocking, respectively, for anteroposterior fields (AP) and lateral fields (Lat); HART $=$ hyperfractionated accelerated radiotherapy.

yet to be defined and a larger Phase II trial is currently ongoing. Preoperative chemotherapy may not be needed in conjunction with preoperative accelerated radiotherapy to get the best local effect, but it is probably required for its systemic effect. However, to keep overall treatment time for local control as short as possible, we aim at adding chemotherapy as an adjuvant immediately after surgery. However, the final impact of preoperative accelerated radiotherapy should be compared to a "standard" treatment emerging from currently ongoing trials within the frame of a randomized multicentric trial.

\section{CONCLUSIONS}

Our initial experience of accelerating radiotherapy in a postoperative setup and the feasibility of low-dose preoperative acceleration in locally advanced rectal cancer formed the basis of the moderate dose preoperative acceleration in rectal cancer rapidly followed by surgery. The lack of a significant toxicity, the high resection rate, the short interval between radiation and surgery, and the reduction of small bowel volume as compared to postoperative irradiation have been used as rationales to start a multicentric Phase II study.

\section{REFERENCES}

1. Aleman, B. M. P.; Lebesque, J. V.; Hart, A. A. M. Postoperative radiotherapy for rectal and rectosigmoid cancer: The impact of total dose on local control. Radiother. Oncol. 25:203-206; 1992.

2. Balslev, I.; Pedersen, M.; Teglbjaerg, P. S.; Hanberg-Soerensen, F.; Bone, J.; Jacohsen, N. O.; Overgaard, J.; Sell, A.; Bertelsen, K.; Hage, E.; Fenger, C.; Kronborg, O.; Hansen, L.; Hoestrup, H.; Noergaard-Pedersen, B. Postoperative radiotherapy in Dukes' $B$ and $C$ carcinoma of the rectum and rectosigmoid. A randomized multicenter study. Cancer 58:22-28; 1986.

3. Begg, A. C.; McNally, N. J.; Shrieve, D. C.; Kärcher, H. A method to measure the DNA synthesis and the potential doubling time from a single sample. Cytometry 6:620-626; 1985.

4. Boulis-Wassif, S.; Gerard, A.; Loygue, J.; Camelot, D.; Buyse, M.; Duez, N. Final results of a randomized trial on the treatment of rectal cancer with preoperative radiotherapy alone or in combination with 5-Fluorouracil, followed by radical surgery. Trial of the European Organization on Research and Treatment of Cancer Gatrointestinal Tract Cancer Cooperative Group. Cancer 53:1811-1818; 1984.

5. Chan, A.; Wong, A.; Langevin, J.; Khoo, R. Preoperative concurrent 5-fluorouracil infusion, mitomycin $\mathrm{C}$ and pelvic irradiation therapy in tethered and fixed rectal carcinoma. Int. J. Radiat. Oncol. Biol. Phys. 25:791-799; 1993.

6. Clarke, D. H.; Lê, M. G.; Sarrazin, D.; Lacombe, M.-J.; Fontaine, F.; Travagli, J.-P.; May-Levin, F.; Contesso, C.; Arriagada, R. Analysis of local-regional relapses in patients with early breast cancers treated by excision and radiotherapy: Experience of the Institute Gustave-Roussy. Int. J. Radiat. Oncol. Biol. Phys. 11:137-145; 1985.

7. Coucke, P. A. Postoperative radiation therapy for rectal cancer: A comment on the interim analysis of a prospective, randomized multicenter trial in the Netherlands. Cancer $12: 3016-3017 ; 1992$.
8. Coucke, P. A.; Cuttat, J.-F.; Mirimanoff, R. O. Adjuvant postoperative accelerated hyperfractionated radiotherapy in rectal cancer: A feasability study. Int. J. Radiat. Oncol. Biol. Phys. 27:885-889; 1993.

9. Cox, J. D.; Guse, C.; Asbell, S.; Rubin, P.; Sause, W. T. Tolerance of pelvic normal tissues to hyperfractionated radiation therapy: Results of protocol 83-08 of the Radiation Therapy Oncology Group. Int. J. Radiat. Oncol. Biol. Phys. 15:1331-1336; 1988.

10. Fisher, B.; Wolmark, N.; Rockette, H.; Redmond, C.; Deutsch, M.; Wickerham, D. L.; Fisher, E. R.; Caplan, R.; Jones, J.; Lerner, H.; Gordon, P.; Feldman, M.; Cruz, A.; Legault-Poisson, S.; Wexler, M.; Lawrence, W.; Robidoux, A.; other NASBP investigators. Postoperative adjuvant chemotherapy or radiation therapy in rectal cancer: Results from NSABP Protocol R-01. J. Natl. Cancer Inst. 80:21 $29 ; 1988$.

11. Fortier, G. A.; Constable, W. C.; Meyers, H.; Wanebo, H. J. Preoperative radiation therapy for rectal cancer. An effective therapy in need of a clinical trial. Arch. Surg. 121:1380-1385; 1986.

12. Fowler, J. F. Potential for increasing the differential response between tumors and normal tissues: Can proliferation rate be used. Int. J. Radiat. Oncol. Biol. Phys. 12:641 $645 ; 1986$.

13. Fowler, J. F.; Lindstrom, M. J. Loss of local control with prolongation in radiotherapy. Int. J. Radiat. Oncol. Biol. Phys. 23:457-467; 1992.

14. Gallagher, M. J.; Brereton, H. J.; Rostock, R. A.; Tero, J. M.; Zekoski, D. A.; Poyss, L. F.; Richter, M. P.; Kligerman, M. M. A. A prospective study of treatment techniques to minimize the volume of pelvic small bowel with reduction of acute and late effects associated with pelvic irradiation. Int. J. Radiat. Oncol. Biol. Phys. 12:1565-1573; 1986.

15. Gerard, A.; Buyse, M.; Nordlinger, B.; Loygue, J.; Péne, F.; Kempf, P.; Bosset, J.-F.; Gignoux, M.; Arnaud, J.-P.; 
Desaive, C.; Duez, N. Preoperative radiotherapy as adjuvant treatment in rectal cancer. Final results of a randomized study of the European Organization for Research and Treatment of Cancer (EORTC). Ann. Surg. 208:606-614; 1988.

16. Gerard, A.; Metzger, U.; Buyse, M. Adjuvant therapy in colorectal cancer. Anticancer Res. 9:1033-1036; 1989.

17. Gunderson, L. L.; Dosoretz, D. E.; Hedberg, S. E.; Blitzer, P. H.; Rodkey, G.; Hoskins, B.; Shipley, W. U.; Cohen, A. C. Low-dose preoperative irradiation, surgery, and elective postoperative radiation therapy for resectable rectum and rectosigmoid carcinoma. Cancer 52:446-451; 1983.

18. Gunderson, L. L.; Russell, A. H.; Llewellyn, H. J.; Doppke, K. P.; Tepper, J. E. Treatment planning for colorectal cancer: Radiation and surgical techniques and value of small bowel films. Int. J. Radiat. Oncol. Biol. Phys. 11:1379$1393 ; 1985$.

19. Haghbin, M.; Sischy, B.; Hinson, J. Combined modality preoperative therapy in poor prognostic rectal adenocarcinoma. Radiother. Oncol. 13:75-81; 1988.

20. Higgins, G. A.; Conn, J. H.; Jordan, P. H.; Humprey, F. W.; Roswit, B.; Keehn, R. J. Preoperative radiotherapy for colorectal cancer. Ann. Surg. 181:624-630; 1975.

21. Higgins, G. A.; Humprey, E. W.; Dwight, R.; Roswit, B.; Lee, L. E.; Keehn, R. J. Preoperative radiation and surgery for cancer of the rectum. Veterans Administration Surgical Oncology Group Trial II. Cancer 58:352-359; 1986.

22. Horn, A.; Morild, I.; Dahl I. Tumour shrinkage and down staging after preoperative radiation of rectal adenocarcinomas. Radiother. Oncol. 18:19-28; 1990.

23. Izar, F.; Fourtanier, G.; Pradere, B.; Chiotasso, P.; Bloom, E.: Fontes-Dislaire, I.; Bugat, R.; Daly, N. Preoperative radiotherapy as adjuvant treatment in rectal cancer. World J. Surg. 16:106-112; 1992.

24. Krook, J. E.; Moertel, C. G.; Gunderson, L. L.; Wieand, H. S.; Collins, R. T.; Beart, R. W.; Maillard, J. A.; Twito, D. I.; Morton, R. F.; Veeder, M. H.; Witzig, T. E.; Cha, S.; Vidyarthi, S. C. Effective surgical adjuvant therapy for high-risk rectal carcinoma. N. Engl. J. Med. 324:709-715; 1991.

25. Minsky, B. D.; Cohen, A. M.; Enker, W. E.; Sigurdson, E. Phase I/II trial of preoperative radiation therapy and coloanal anastomosis in distal invasive resectable rectal cancer. Int. J. Radiat. Oncol. Biol. Phys. 23:387-392; 1992.

26. Minsky, B. D.; Cohen, A.; Enker, W. E.; Sigurdson, E.; Harrison, L. B. Radiation therapy for unresectable rectal cancer. Int. J. Radiat. Oncol. Biol. Phys. 21:1283-1289; 1991.

27. Minsky, B. D.; Cohen, A. M.; Kemeny, N.; Enker, W. E.; Kelsen, D. P.; Schwartz, G.; Saltz, L.; Dougherty, J.; Frankel, J.; Wiseberg, J. Preoperative combined 5-FU, low-dose leucovorin, and sequential radiation therapy for unresectable rectal cancer. Int. J. Radiat. Oncol. Biol. Phys. 25:821 $827 ; 1993$.

28. Minsky, B. D.; Kemcny, N.; Cohen, A.; Enker, W. E.; Kelsen, D. P.; Reichman, B.; Saltz, L.; Sigurdson, E. R.; Frankel, J. Preoperative high-dose leucovorin/5-fluorouracil and radiation therapy for unresectable rectal cancer. Cancer 67:2859-2866; 1991 .

29. Minsky, B. D.; Mies, C.; Recht, A.; Rich, T. A.; Chaffey, J. T. Resectable adenocarcinoma of the rectosigmoid and rectum. Patterns of failure and survival. Cancer 61:14081416; 1988.

30. Mohiuddin, M.; Ahmad, N. R. Preoperative chemoradiation for advanced rectal cancer. Int. J. Radiat. Oncol. Biol. Phys. 25:923-924; 1993

31. Mohiuddin, M.; Marks, G. High dose preoperative irradia- tion for cancer of the rectum, 1976-1988. Int. J. Radiat. Oncol. Biol. Phys. 20:37-43; 1991.

32. MRC Working Party, Second report: The evaluation of low dose preoperative X-ray therapy in the management of operable rectal cancer: Results of a randomly controlled trial. Br. J. Surg. 71:21-25; 1984.

33. NIH Consensus Conference. Adjuvant therapy for patients with colon and rectal cancer. JAMA 19:1444-1450; 1990.

34. Pahlman, L.; Glimelius, B. Pre- or postoperative radiotherapy in rectal and rectosigmoid carcinoma. Ann. Surg. 211:187-195; 1990.

35. Pahlman, L.; Glimelius, B.; Ginman, C.; Graffman, S.; Adalsteinsson, B. Preoperative irradiation of primarily nonresectable adenocarcinoma of the rectum and rectosigmoid. Acta Radiol. Oncol. 24:35-39; 1985.

36. Rew, D. A.; Wilson, G. D.; Taylor, I.; Weaver, P. C. Proliferation characteristics of human colorectal carcinomas measured in vivo. Br. J. Surg. 78:60-66; 1991.

37. Rider, W. D.; Palmer, J. A.; Mahoney, L. J.; Robertson, C. T. Preoperative irradiation in operable cancer of the rectum: Report of the Toronto trial. Can. J. Surg. 20:235$238 ; 1977$.

38. Schilsky, R. L.; Brachman, D. G. Adjuvant chemotherapy and radiation therapy in colorectal cancer. Principles and Practice of Oncology. vol. 6. Philadelphia, PA: J. B. Lippincott; 1992:1-12.

39. Shank, B.; Enker, W.; Santana, J.; Morrissey, K.; Daly, J.; Quan, S.; Knapper, W. Local control with preoperative radiotherapy alone vs. "sandwich" radiotherapy for rectal cancer. Int. J. Radiat. Oncol. Biol. Phys. 13:11-115; 1987.

40. Stearns, M. W.; Deddish, M. R.; Quan, S. H.; Leaming, R. H. Preoperative roentgen therapy for cancer of the rectum and rectosigmoid. Surg. Gynecol. Obstet. 138:584$586 ; 1974$.

41. Steel, G. Combined modality therapy of rectal carcinomaThe time has come. N. Engl. J. Med. 324:764-766; 1991.

42. Stockholm Rectal Cancer Study Group: Short term preoperative radiotherapy for adenocarcinoma of the rectum. Am. J. Clin. Oncol. 10:369-375; 1987.

43. Taylor, I.; Nortover, J. M. A. Adjuvant therapy in colorectal cancer: The need for a mega-trial. Br. J. Surg. 77:841-842; 1990.

44. Tepper, J. E. Adjuvant irradiation of gastrointestinal malignancies. Impact on local control and tumor cure. Int. J. Radiat. Oncol. Biol. Phys. 12:667-671; 1986.

45. Tepper, J. E. Role of radiation therapy in the treatment of carcinoma of the rectum. J. Surg. Oncol. Suppl. 2:51-53; 1991.

46. Tepper, J. E.; Cohen, A. M.; Wood, W. C.; Orlow, E. L.; Hedberg, S. E. Postoperative radiation therapy of rectal cancer. Int. J. Radiat. Oncol. Biol. Phys. 13:5-10; 1987.

47. Tepper, J. E.; Wood, W. C.; Cohen, A. M. Treatment of locally advanced rectal cancer with external beam radiation, surgical resection, and intraoperative radiation therapy. Int. J. Radiat. Oncol. Biol. Phys. 16:1437-1444; 1989.

48. Terry, N. H. A.; Meistrich, M. L.; White, R. A.; Rich, T. A.; Peters, L. J. Cell kinetic measurements as predictors of response of human tumors to radiotherapy and chemotherapy. Cancer Bull. 44:124-129; 1992.

49. Thomas, P. R. M.; Lindblad, A. S. Adjuvant postoperative radiotherapy and chemotherapy in rectal carcinoma: $A$ review of the Gastrointestinal Tumor Study Group experience. Radiother. Oncol. 13:245-252; 1988.

50. Tobin, R. L.; Mohiuddin, M.; Marks, G. Preoperative irradiation for cancer of the rectum with extrarectal fixation. Int. J. Radiat. Oncol. Biol. Phys. 21:1127-1132; 1991.

51. Treurniet-Donker, A. D.; van Putten, W. L. J.; Wereldsma, 
J. C. J.; Bruggink, E. D. M.; Hoogenraad, W. J.; Roukema, J. A.; Snijders-Keilholz, A.; Meijer, W. S.; Meerwaldt, J. H.; Wijnmaalen, A. J.; Wiggers, T. Postoperative radiation therapy for rectal cancer. An interim analysis of a prospective randomized multicenter trial in the Netherlands. Cancer 67:2042-2048; 1991.

52. Trotti, A.; Klotch, D.; Endicott, J.; Ridley, M.; Greenberg, H. A prospective trial of accelerated radiotherapy in the postoperative treatment of high-risk squamous cell carcinoma of the head and neck. Int. J. Radiat. Oncol. Biol. Phys. 26:13-21; 1993.

53. Willett, C. G.; Shellito, P. C.; Rodkey, G. V.; Wond,
W. C. Preoperative irradiation for tethered rectal carcinoma. Radiother. Oncol. 21:141-142; 1991.

54. Wilson, G. D.; McNally, N. J.; Dische, S.; Saunders, M. I.; Des Rochers, C.; Lewis, A. A.; Bennett, M. H. Measurement of cell kinetics in human tumors in vivo using bromodeoxyuridine incorporation and flow cytometry. $\mathrm{Br}$. J. Cancer 58:423-431; 1988.

55. Withers, R. H. Biologic basis for altered fractionation schemes. Cancer 58:2086-2095; 1985.

56. Withers, R. H.; Taylor, J. M. G.; Maciejewski, B. The hazard of accelerated tumor clonogen repopulation during radiotherapy. Acta Oncol. 27:131-146; 1988. 